\title{
Carriage of Gardnerella vaginalis and anaerobes in semen
}

\author{
C A ISON AND C S F EASMON
}

From the Department of Medical Microbiology, Wright-Fleming Institute, St Mary's Hospital Medical School, London W2 IPG

SUMMARY Gardnerella vaginalis was isolated from $22(38 \%)$ of 58 semen samples obtained from men attending an infertility clinic. Counts ranged from $1.2 \times 10^{3}$ to $>10^{7}$ colony forming units (cfu) $/ \mathrm{ml}$. There was no association between the isolation of $G$ vaginalis and the sperm count. Twenty $(34 \cdot 4 \%)$ samples contained non-sporing anaerobes and nine $(15 \cdot 5 \%)$ both anaerobes and $G$ vaginalis. The infective dose of $G$ vaginalis is not known, but semen could act as a medium for its sexual transmission.

\section{Introduction}

Bacterial vaginosis (non-specific vaginitis) is a condition that has been associated with the isolation of Gardnerella vaginalis ${ }^{1}$ and non-sporing anaerobes. ${ }^{23}$ It is not yet clear whether the condition is sexually transmitted or simply associated with sexual activity.

Evldence for sexual transmission has rested on the high prevalence of $G$ vaginalis in the urine $e^{4}$ and urethra of sexual contacts of infected women. ${ }^{1256}$

If $G$ vaginalis (or anaerobes) associated with bacterial vaginosis are sexually transmitted, the likely medium would be semen. We have examined semen for the presence of these organisms to assess its role in the causation and recurrence of bacterial vaginosis.

\section{Patients and methods}

\section{PATIENT SELECTION}

Semen samples are collected routinely from the male partner of all new couples attending the subfertility clinic at the Samaritan Hospital for Women, London. Samples were tested within four hours of collection for: $\mathrm{pH}$ (using narrow range $\mathrm{pH}$ paper, British Drug Houses, London, UK), total sperm count, and the presence of "clue" cells (wet and Gram stained preparations), $G$ vaginalis, and anaerobes. The viscosity of semen and the presence of abnormal forms and motility of sperms were

Address for reprints: Professor C S F Easmon, Department of Medical Microbiology, Wright-Fleming Institute, St Mary's Hospital Medical School, London W2 1PG

Accepted for publication 25 June 1984 investigated but not recorded for the purpose of this study.

ISOLATION AND IDENTIFICATION OF BACTERIA $G$ vaginalis was isolated on bilayer human blood agar made selective by adding gentamicin, nalidixic acid, and amphotericin B. ${ }^{7}$ Numbers of $G$ vaginalis were estimated by inoculating $10 \mu \mathrm{l}$ of tenfold dilutions of semen on the same medium without added antibiotics. All media were incubated at $37^{\circ} \mathrm{C}$ for 48 hours in $5 \%$ carbon dioxide. All colonies that gave diffuse $\beta$ haemolysis on human but not on horse blood agar, were Gram variable bacilli, and oxidase and catalase negative were identified as $G$ vaginalis. The identity of some strains was confirmed further by the methods previously described by Piot et $a l,{ }^{8}$ including the ability to hydrolyse hippurate to produce $\alpha$ and $\beta$ glucosidase and acid from starch, maltose, and mannitol, and to be inhibited by metronidazole $50 \mu \mathrm{g}$, nitrofurantoin $150 \mu \mathrm{g}$, and bile $10 \%$.

Obligate anaerobes were isolated on enriched blood agar, alone or with added kanamycin and vancomycin as previously described. ${ }^{9}$ After five days' incubation in an anaerobic cabinet (Don Whitley, West Yorkshire, UK) all strict anaerobes were identified by established criteria as described by Holdeman et al. ${ }^{10}$

\section{Results}

Semen samples were collected from 58 men. The pH of all samples was $7 \cdot 0$ to $8 \cdot 0$. In only $2 / 58$ samples were "clue" cells seen. $G$ vaginalis was isolated from $22(37.9 \%)$ men, anaerobes from $20(34.5 \%)$, and both groups of organisms from nine $(15 \cdot 5 \%)$. There 
was no association between the isolation rate of either $G$ vaginalis or anaerobes and the total sperm count (table I).

TABLE I Relation of sperm count in 58 men to isolation of Gardnerella vaginalis and anaerobes

\begin{tabular}{lccl}
\hline & \multicolumn{3}{c}{ No (\%) patients colonised with: } \\
\cline { 2 - 3 } Sperm count $(\times 106 / \mathrm{ml})$ & $G$ vaginalis & Anaerobes & $\begin{array}{l}\text { G vaginalis } \\
\text { and anaerobes }\end{array}$ \\
\hline Nil $(\mathrm{n}=6)$ & $2(33)$ & $2(33)$ & 0 \\
$1-28(\mathrm{n}=22)$ & $7(32)$ & $7(32)$ & $3(14)$ \\
$>28(\mathrm{n}=30)$ & $13(43)$ & $11(37)$ & $6(20)$ \\
\hline
\end{tabular}

All strains of $G$ vaginalis were identified by differential haemolysis, Gram stain, and the absence of oxidase and catalase, and 13/22 were further identified as described above and were apparently consistent with published criteria for identifying $G$ vaginalis. All anaerobes identified belonged to either the genus Bacteroides or Fusobacterium, B bivuis and $B$ disiens being the predominant species (table II). The range and prevalence of anaerobes isolated were the same when found in association with $G$ vaginalis (table II).

TABLE II Identification of anaerobes alone or with Gardnerella vaginalis in semen from 58 men

\begin{tabular}{lll}
\hline & \multicolumn{2}{l}{ No of isolates found: } \\
\cline { 2 - 3 } & $\begin{array}{ll}\text { Total } \\
\text { tested }(n=20)\end{array}$ & $\begin{array}{l}\text { In association with } \\
\text { G vaginalis }(\boldsymbol{n}=9)\end{array}$ \\
\hline Bacteroides bivius & 5 & 4 \\
Bacteroides disiens & 5 & 2 \\
Bacteroides capillosus & 4 & 2 \\
Bacteroides oralis & 1 & 0 \\
Bacteroides ruminicola & 2 & 1 \\
Other Bacteroides spp & 4 & 3 \\
Fusobacterium spp & 3 & 2 \\
Unidentified & 9 & 5 \\
\hline
\end{tabular}

In $9 / 22$ patients from whom $G$ vaginalis was isolated quantitative counts were available. These ranged from $1.2 \times 10^{3}$ to $>10^{7} \mathrm{cfu} / \mathrm{ml}$. Only two patients had counts higher than $10^{6} \mathrm{cfu} / \mathrm{ml}$. The geometric mean was $9 \times 10^{4} \mathrm{cfu} / \mathrm{ml}$.

\section{Discussion}

Ideally, a study of the role of semen in bacterial vaginosis would include taking vaginal swabs from the women, and urethral and semen samples from their male partners. This type of study, however, is difficult to organise. Our series of semen samples, although they may not be truly representative, allow preliminary data to be collected on a readily available and sexually active group. Although $48 \%$ of patients had a low sperm count $\left(<28 \times 10^{6} / \mathrm{ml}\right)$, only $6 / 58$ had azoospermia. Whereas there is no absolute correlation between a low sperm count and infertility, the count is generally lower in infertile men. The prevalence of $G$ vaginalis and anaerobes was similar in men with varying sperm counts in this study, and there therefore appeared to be no indication that these organisms relate to infertility in men.

$G$ vaginalis has been implicated as the aetiological agent in bacterial vaginosis. ${ }^{1}$ If this condition is to be classed as sexually transmitted it would need to be present in semen in sufficient numbers to provide an infective dose.

Work with human volunteers suggests that the infective dose of $G$ vaginalis may be high. Criswell $e t$ al did not succeed in infecting all their subjects using an inoculum of $10^{9} \mathrm{cfu} .{ }^{11}$ In contrast, an inoculum of only $10^{5} \mathrm{cfu}$ was sufficient to establish colonisation with $G$ vaginalis in pigtail macacque monkeys in which the vaginal $\mathrm{pH}$ was high and large numbers of anaerobes were present. ${ }^{12}$ The true infective dose of $G$ vaginalis is not known.

If the figure of Criswell $e t$ al is taken, then the counts of $G$ vaginalis that we found in semen, if representative, would be far too low to be infective. There are, however, two factors that Criswell et al did not take into account: firstly, any effects of semen itself in helping to establish infection with gardnerella, possibly by promoting bacterial growth or adherence or by raising vaginal $\mathrm{pH}$; and secondly the presence of non-sporing anaerobes.

Anaerobes, ${ }^{23}$ either alone or in combination with $G$ vaginalis, ${ }^{13}$ have been suggested as causative agents of bacterial vaginosis, but there are no corresponding data to suggest a possible infective dose or indeed sexual transmission. There is also little information on the carriage of anaerobes in men, but our own work (unpublished data) suggests that their isolation from the urethra is similar to their prevalence in semen. Gardner and Dukes ${ }^{1}$ showed that vaginosis was established in more volunteers using vaginal material than using pure cultures of $G$ vaginalis, which suggested that other factors such as the presence of anaerobes might be involved.

The isolation of $G$ vaginalis from semen raises again the question of whether this organism colonises men and provides a reservoir for reinfection or is transient, being merely the result of continued passive acquisition from the female. Urethral carriage of $G$ vaginalis in unselected men is between $7 \%$ and $11 \%,{ }^{14}$ is four times less than we found in semen $(37 \cdot 9 \%)$. This difference is unexplained as we 
were unable to obtain urethral samples from the patients in the study. It emphasises the need for taking both urethral and semen samples, together with vaginal material from the female partner, to clarify the role of semen as a means of sexual transmission in bacterial vaginosis.

We thank the Medical Research Council for financial support.

\section{References}

1. Gardner $\mathrm{HL}$, Dukes CD. Haemophilus vaginalis vaginitis. A new defined specific infection previously classified as "nonspecific vaginitis" Am J Obstet Gynecol 1955;69:962-76.

2. Pheifer TA, Forsyth PS, Durfee MA, Pollock HM, Holmes KK. Non-specific vaginitis. Role of Haemophilus vaginalis and treatment with metronidazole. $N$ Engl J Med 1978; 298: 1429-34.

3. Spiegel CA, Amsel R, Eschenbach D, Schoenknecht $F$, Holmes KK. Anaerobic bacteria in non-specific vaginitis. $N$ Engl J Med 1980;303:601-6.

4. Leopold $\mathrm{S}$. Heretofore undescribed organism isolated from the genito-urinary system. United States Armed Forces Medical Journal 1953;4:263-6.
5. Gardner HL, Dukes CD. Haemophilus vaginalis vaginitis. Ann NY Acad Sci 1959; 83:280-9.

6. Blackwell A, Barlow D. Clinical diagnosis of anaerobic vaginosis (non-specific vaginitis). British Journal of Venereal Diseases 1982; 58:387-93.

7. Ison CA, Dawson SG, Hilton J, Csonka G, Easmon CSF. A comparison of culture and microscopy in the diagnosis of Gardnerella vaginalis infection. J Clin Pathol 1982;35:550-4.

8. Piot P, Van Dyck E, Totten PA, Holmes KK. Identification of Gardnerella (Haemophilus) vaginalis. J Clin Microbiol 1982; 15: 19-24.

9. Ison CA, Easmon CSF, Dawson SG, Southerton G, Harris JWR. Non-volatile fatty acids in the diagnosis of non-specific vaginitis. J Clin Pathol 1983; 36: 1367-70

10. Holdeman LV, Cato EP, Moore WEC, eds. Anaerobic laboratory manual 4th ed. Blacksburg,United States: Virginia Polytechnic Institute and State University, 1977.

11. Criswell BS, Ladwig CL, Gardner HL, Dukes CD. Haemophilus vaginalis: vaginitis by inoculation from culture. Obstet Gynecol 1969;33: 195-9.

12. Johnson AP, Ison CA, Hetherington CM, et al. A study of the susceptibility of three species of primate to vaginal colonisation with Gardnerella vaginalis. Br J Exp Pathol 1984; 65: 389-96.

13. Chen KCS, Forsyth PS, Buchanan TM, Holmes KK. Amine content of vaginal fluid from untreated and treated patients with non-specific vaginitis. J Clin Invest 1979;63:828-35.

14. Kinghorn G, Jones BM, Chowdhury FH, Greary I. Balanoposthitis associated with Gardnerella vaginalis infection in men. British Journal of Venereal Diseases 1982; 58: 127-9.

15. Dawson SG, Ison CA, Csonka G, Easmon CSF. Male carriage of Gardnerella vaginalis. British Journal of Venereal Diseases 1982;58:243-5. 